\title{
Anaerobic digestion of lipid-extracted Auxenochlorella protothecoides biomass for methane generation and nutrient recovery
}

Authors: Pavlo Bohutskyi ${ }^{1}$, Ben Ketter $^{2}$, Steven Chow $^{1}$, Kameron Adams ${ }^{1}$, Michael J.

Betenbaugh $^{2}$, F. C. Thomas Allnutt ${ }^{3,4}$, Edward J. Bouwer ${ }^{1}$

Affiliations:

${ }^{1}$ Department of Geography \& Environmental Engineering, Johns Hopkins University, 3400 North Charles Street, Baltimore, MD 21218-2686 USA

${ }^{2}$ Department of Chemical \& Biomolecular Engineering, Johns Hopkins University, 3400

North Charles Street, Baltimore, MD 21218-2686 USA

${ }^{3}$ Phycal Inc., 51 Alpha Park, Highland Heights, OH 44143 USA

${ }^{4}$ Current Address: BrioBiotech, P.O. Box 26, Glenelg, MD 21737 USA

* Corresponding author, email: bohutskyi@jhu.edu, phone: (443) 794-1780

\begin{abstract}
This study evaluated methane production and nutrient recovery from industrially produced, lipid extracted, algal biomass (LEA) of Auxenochlorella protothecoides using semicontinuous anaerobic digestion (AD) at different organic loading rates (OLRs) and hydraulic retention times (HRTs). It was shown, that AD can improve biofuel production
\end{abstract}


efficiency and sustainability, especially for scaled processes, through up to $30 \%$ increase in energy generation (up to $0.25 \mathrm{~L}$ of methane per g of LEA volatile solids) and partial nutrient recovery and recycling. The nutrient recycling with the AD effluent may reduce the cost of the supplied fertilizers by up to $45 \%$. However, methane production was limited to nearly $50 \%$ of theoretical maxima potentially due to biomass recalcitrance and inhibition effects from the residual solvent in the LEA. Therefore, further AD optimization is required to maximize methane yield and nutrient recovery as well as investigation and elimination of inhibition from solvent residues.

Keywords: biogas production; inhibition by solvent residues; integrated biodiesel and methane production; nitrogen and phosphorus recycling; trace element recovery; process sustainability

\section{Introduction}

The recent expansion of interest in renewable and sustainable microalgal biofuels is driven by rising energy demand and higher prices coupled with society's growing awareness of exhaust gas emissions associated with the world's continued overreliance on fossil fuels. The use of microalgal biomass for feedstocks for fuel production has several key advantages: 1) photosynthetic productivities higher than terrestrial plants, 2) possible cultivation on non-arable lands, 3) entire organism available for conversion, and 4) easy integration with industrial $\mathrm{CO}_{2}$ generation point sources for productive reuse (Schenk et al., 2008). However, several technological and economic hurdles need to be managed in order to demonstrate market viability as an efficient and sustainable industrial algal biofuel process. 
Considerable attention has been given to converting the lipid fraction of algal biomass into biodiesel or green diesel. These processes have demonstrated production of liquid drop-in fuels for motor vehicles and jets from the lipid fraction. However, these processes only utilize the lipid fraction of algal biomass. The residual biomass after lipid extraction is composed mostly of carbohydrate and protein fractions and can represent 30$70 \%$ of the ash free dry weight (AFDW) of the overall dry biomass harvested (Bohutskyi \& Bouwer, 2013). Recent progress demonstrated the potential to minimize the amount of lipid extracted algal residues (LEA) generated by inducing the cell lipid content up to 50$70 \%$ by applying environmental stress (nutrient starvation or exposure to extreme salt content, $\mathrm{pH}$, temperature, radiation, or inhibiting chemicals) (Gao et al., 2013), providing an excess of organic carbon substrate (e.g., sugar) to employ heterotrophic growth conditions ( $\underline{\text { Bohutskyi et al., 2014b) }}$, or modifying the lipid metabolic pathways ( $\underline{\text { Yu et al., }}$ 2011). Unfortunately, these methods can either compromise the algal growth rate, require supplementation by expensive glucose, or are still in the development stage. Additionally, certain types of algal strains, especially those that grow competitively in open ponds or even wastewater, have low lipid contents (e.g., 5-20\% AFDW) and might not be easily replaced with the lipid-rich microalgae species due to competition and/or contamination under open pond culturing conditions. Therefore, it is critical to develop biofuel production technologies that make use of the entire algal biomass (e.g., lipid and LEA) to maximize energy productivity and pass the threshold for algal biofuels to be cost competitive. Some of the options are to produce high value co-products (self-limiting markets when algal biofuels are at commercial scale) or conversion of LEA into additional fuel. Anaerobic digestion (AD) is an established, scalable technology that can be used to transform LEA or 
whole algal biomass into the biofuel methane (Bohutskyi \& Bouwer, 2013). Furthermore, the preliminary studies under batch conditions using the biomethane potential procedure (anaerobic medium amended with nutrients, vitamins, $\mathrm{pH}$ and redox buffers) performed in our laboratories as well as other laboratories demonstrated that the use of $\mathrm{AD}$ for conversion of LEA residues was possible (Bohutskyi et al., 2014b; Hernandez et al., 2014; Zhao et al., 2014). In addition, integration of $\mathrm{AD}$ in the algae-to-biofuel process provides the potential for recycling part of the nutrients to further reduce the overall costs of the biofuel production process (Bohutskyi et al., 2014c). The investigation of LEA anaerobic digestion in continuous bioreactors at conditions more similar to industrial application is a critical step in scaling up this technology.

Reuse and recycling most of the macro- and micronutrients required for algal growth need to be achieved in order to assure sustainability of the algal biofuels and reduce production costs (Pate et al., 2011). Failure in developing efficient nutrient recycling technology during algal biofuel production will put the industry in competition with agriculture for nutrients (e.g., nitrogen and phosphorus). Generation of 30 billion gallons per year (BGY) of algal biofuel equivalent or nearly $30 \%$ of the US liquid fuel consumption without nutrient recycling would require $130-320 \%$ and $60-150 \%$ of the current nitrogen and phosphorus fertilizer consumption in the U.S., respectively; the ranges depend on the algal biomass lipid content (Pate et al., 2011). Moreover, augmented algal production requires supplying essential trace elements such as $\mathrm{Mg}, \mathrm{Ca}, \mathrm{Mn}, \mathrm{Co}$, and $\mathrm{Mo}$. Importantly, some of these elements are naturally released from degraded biomass into the aqueous phase during the AD process. Previously, it was demonstrated that nitrogen, phosphorus and several trace elements can be partially recovered from algae and LEA with 
AD effluent for recycling to the cultivation stage (Bohutskyi et al., 2014c). However, no data are available on what fraction of the essential macronutrients and trace elements assimilated in algal cells can be recovered from the $\mathrm{AD}$ effluent and also what the impact of the $\mathrm{AD}$ operational parameters will have on the recovery efficiency. To address these issues, a semi-continuous AD system was implemented in order to determine the methane production from the industrially produced Auxenochlorella protothecoides lipid-extracted residues. The amount of nutrients available for recycling was measured and compared to the total nutrient content in LEA. In addition, the current study evaluated the impact of the organic loading rate (OLR) and hydraulic retention time (HRT) on methane production and the amount of recovered macro- and micronutrients. It is believed that these data provide vital insights for the development of an economical and sustainable microalgal biofuel industry.

\section{Materials and methods}

\subsection{Microalgal biomass}

The industrially produced lipid extracted biomass (LEA) of Auxenochlorella (formerly Chlorella) protothecoides was used as substrate for semi-continuous anaerobic digestion in the current study. The LEA was generously provided by Phycal Inc. from its subpilot-scale cultivation facility. The A. protothecoides biomass was generated using a sequential phototrophic-heterotrophic growth system. The alga was cultivated in an open-pond under photoautotrophic conditions followed by cultivation in the fermenter under heterotrophic conditions to boost lipid content and then dewatered using centrifugation (Bohutskyi et al., 2014b). The lipid fraction of the biomass was extracted (see description below) and the slurry of whole algae (WA) and LEA were stored at $-80^{\circ} \mathrm{C}$ until use. 


\subsection{Lipid extraction procedure}

The lipid fraction of the biomass was extracted using acetone followed by hexane as extraction solvents according to the following procedure: $1 \mathrm{~L}$ of $300 \mathrm{~g} / \mathrm{L}$ biomass was transferred in a $4 \mathrm{~L}$ plastic container, mixed with $1 \mathrm{~L}$ of acetone and the $\mathrm{pH}$ of the mixture was adjusted to $\mathrm{pH} 7$ using $10 \mathrm{M} \mathrm{NaOH}$ solution. Next the biomass-acetone mix was processed three times in the Labstar LS1 Bead Mill machine using the following conditions: $617.5 \mathrm{~mL}$ of $0.6-0.8 \mathrm{~mm}$ beads, agitator speed at $2800 \mathrm{rpm}$, pump speed at 85 rpm. Then the DI water was added to the processed slurry with 0.5 to 1 ratio, the solution was mixed, incubated in a water bath at $65^{\circ} \mathrm{C}$ for $20 \mathrm{~min}$ and centrifuged in $50 \mathrm{~mL}$ tubes (containing $30 \mathrm{~mL}$ of solution) at 4,000 rpm for $10 \mathrm{~min}$ (Beckman J21C; $6 \mathrm{~L}$ rotor). Next, $5 \mathrm{~mL}$ of hexane was carefully added into the centrifuge tube containing the biomass and hexane was pumped back and forth several times without disturbing the liquid inside the $10 \mathrm{ml}$ glass pipette. The hexane level containing lipids was transferred into a preweighed $15 \mathrm{~mL}$ glass tube. This step was repeated two more times. The combined hexane phase was transferred into a Zanntek Analytical Evaporator adjusted to $85^{\circ} \mathrm{C}$ and nitrogen flow rate 1.0 SCFH $\left(1 \mathrm{ft}^{3} / \mathrm{hr}\right)$. The lipid content was determined by subtracting the mass of the empty vial from the mass of the vial after hexane evaporation.

\subsection{Anaerobic digestion system description and operation}

The $\mathrm{AD}$ experiments were carried out in a semi-continuous stirred tank reactor using $3 \mathrm{~L}$ spinner flasks (Bellco Glass, Inc., Vineland, NJ, USA) containing $2 \mathrm{~L}$ of the anaerobic culture. The bioreactors were equipped with four sampling ports for solution withdrawal, feeding, biogas collection and sampling for analysis of methane content. The AD systems were operated in a controlled environmental chamber at $35 \pm 1{ }^{\circ} \mathrm{C}$ and continuously mixed 
with a variable-speed overhead drive motor (Bellco Glass) that rotated an acrylic shaft with polyethylene $12 \times 15 \mathrm{~cm}(\mathrm{HxD})$ impellers at $\sim 20 \mathrm{rpm}$. The volume of the produced biogas was measured using wet-tip gas meters (Wet Tip Gas Meter Co., Nashville, TN, USA) equipped with a HOBO Pendant ${ }^{\circledR}$ G Data Logger (Onset Computer Corporation, Bourne, MA, USA). Anaerobic digester-treated sewage sludge (obtained from the Back River Wastewater Treatment Plant, Baltimore, MD, USA) was used as the starter inoculum. The digesters were fed with algal biomass for about 3 months to "washout" sewage sludge residues prior to starting data and sample collection for this study. The anaerobic bioreactor was operated at four different regimes applied sequentially (Table 1). First, the bioreactor was operated at an organic loading rate (OLR) of $1.0 \mathrm{gVS} / \mathrm{L}$-day and hydraulic retention time (HRT) of 20 days (Run 1). The second run was at an OLR 2.0 gVS/L-day and HRT of 20 days (Run 2). The third run was at an OLR $1.0 \mathrm{gVS} / \mathrm{L}$-day and HRT at 40 days (Run 3). The final run was at an OLR $1.5 \mathrm{gVS} / \mathrm{L}-$ day and HRT of 40 days (Run 4).

The AD feedstock solutions were prepared in $2 \mathrm{~L}$ batches by diluting either the frozen WA paste or LEA with Milli-Q ${ }^{\circledR}$ water to obtain the desired VS (volatile solid) content. The LEA solution was homogenized for 10 minutes using an Oster ${ }^{\circledR}$ 10-Speed blender equipped with a $25 \mathrm{~mm}$ radius blade at $27,000 \mathrm{rpm}$ (A. J. Oster Corp., Warwich, CT, USA). The feedstock solutions were stored at $4^{\circ} \mathrm{C}$ and pre-heated to $\sim 30^{\circ} \mathrm{C}$ by microwaving for approximately 1 minute prior to usage (Emerson, St. Louis, MO, USA). The manual withdrawal of digested algae and addition of the algal feedstock was done once a day using a $60 \mathrm{~mL}$ syringe. The collected digestate samples were stored in a $-20^{\circ} \mathrm{C}$ freezer until use. For nutrient analysis, the samples were thawed at room temperature, then centrifuged in $50 \mathrm{~mL}$ tubes at $4,200 \mathrm{rpm}(4,000 \times \mathrm{g})$ and $4{ }^{\circ} \mathrm{C}$ for $5 \mathrm{~min}$. The supernatant was 
separated, filtered through a $0.22 \mu \mathrm{m}$ nylon syringe filter and used to measure nutrient concentration. The data points were generated from digestate samples collected on different days (2-4 days) at the end of every run and reported as the average with standard deviation provided.

\subsection{Estimation of energy production from algal biomass}

Theoretical methane yield was estimated from the algal biomass' elemental composition achieved in this study using the modified Buswell formula (Equation 1) (Buswell \& Mueller, 1952):

$\mathrm{C}_{c} \mathrm{H}_{h} \mathrm{O}_{o} \mathrm{~N}_{n} \mathrm{~S}_{s}+y\left(\mathrm{H}_{2} \mathrm{O}\right) \rightarrow x\left(\mathrm{CH}_{4}\right)+(c-x) \mathrm{CO}_{2}+n\left(\mathrm{NH}_{3}\right)+s\left(\mathrm{H}_{2} \mathrm{~S}\right)$

where: $c, h, o, n$ and $s$ are determined from the biomass elemental composition and stoichiometric coefficients $x$ and $y$ are calculated as: $x=(4 c+h-2 o-3 n-2 s) / 8$ and $y$ $=(4 c-h-2 o+3 n+2 s) / 4$

The energy yield from algal biomass was calculated using specific energy 39.5 MJ/kg and $37.1 \mathrm{MJ} / \mathrm{m}^{3}$ for triacylglycerols (TAGs) and methane respectively. The detailed calculations are shown in Supplementary data (Appendix A).

\subsection{Calculation of nutrient costs and requirement for scaled up process}

To make these calculations the following techniques and assumptions were applied. The nutrients required for biodiesel production were estimated based on the elemental analysis of whole A. protothecoides biomass or based on part of the supplied nutrients assimilated by algae during cultivation. The nutrients remaining in the spent growth medium were assumed to be all recycled to the cultivation system. Similarly, the fertilizers used for production of glucose provided for algal growth at heterotrophic conditions were left out of the current calculations. The content of biodiesel-convertible lipids in biomass was 
assumed equal to content of neutral lipids or TAGs with volumetric density $0.92 \mathrm{~kg}$ per liter (Pate et al., 2011). The bulk prices for chemical fertilizer were obtained using the www.alibaba.com sales service web portal. Then, the required amount of nutrients was estimated for algal bioenergy production that would replace $10 \%$ of the liquid fuel consumption in the U.S. or 29 billion gallons per year (BGY) by algal biofuels (USEIA, 2013). Finally, this calculated fertilizer requirement was compared to the agricultural nutrient consumption reported in the U.S. in 2011 (USGS, 2014) to estimate the impact of nutrient recycling on sustainability of algal biofuel production. The detailed calculations are shown in Supplementary data (Appendix B).

\subsection{Analytical techniques}

Algal biomass was analyzed to determine total solids (TS) and volatile solids (VS) according to the Standard Methods for the Examination of Water and Wastewater (Eaton \& Franson, 2005). Carbohydrate content was determined by the phenol-sulfuric acid method using glucose as the standard. Crude protein was estimated by multiplication of total nitrogen in the LEA by a correction factor of 6.25 . The content of $\mathrm{C}, \mathrm{H}, \mathrm{O}$ and $\mathrm{N}$ of freeze-dried WA and LEA was determined by a subcontractor laboratory (Micro Analysis, Inc., Wilmington, DE, USA) using a \%CHN Analyzer. The content of trace elements in biomass samples was measured using microwave-assisted digestion (CEM Mars Xpress, Matthews, NC, USA) in concentrated nitric acid (TraceMetal ${ }^{\mathrm{TM}}$ Grade, Fisher Chemical) followed by analysis on an Elan ${ }^{\circledR}$ DRC ${ }^{\mathrm{TM}}$ II ICP-MS (PerkinElmer/Sciex, Concord, ON, Canada). The detailed description of the procedure has been published previously (Bohutskyi et al., 2014b). 
Hach Kits (Hach USA, Loveland, CO, USA) were used to measure the concentrations of total nitrogen $\left(\mathrm{N}_{\text {tot }}\right)$, ammonia $\left(\mathrm{NH}_{3}\right)$, phosphate $\left(\mathrm{PO}_{4}^{-3}\right)$, and total phosphorus $\left(\mathrm{P}_{\mathrm{tot}}\right)$ in the filtered supernatant of the $\mathrm{AD}$ effluent. The content of trace elements was measured using $1 \mathrm{~mL}$ of the sample spiked with $1 \mathrm{~mL}$ of concentrated $\mathrm{HNO}_{3}$ for microwave-assisted digestion. The metals content of the digestate was subsequently analyzed with an ICP-MS system.

Biogas analysis. Biogas composition was analyzed using a Shimadzu GC equipped with the Hayes Q 80/100 column and thermal conductivity detector (TCD). Helium was used as the carrier gas at 2 bar pressure. The Inj/Det temperature and column current were $130^{\circ} \mathrm{C}$ and $80 \mathrm{~mA}$, respectively. A $250 \mu \mathrm{L}$ sample of biogas was obtained using a Hamilton SampleLock ${ }^{\mathrm{TM}}$ syringe and injected into the GC. The GC-TCD was calibrated by injecting 50,150,150, 200 and $250 \mu \mathrm{L}$ of $\mathrm{N}_{2}, \mathrm{CH}_{4}$ and $\mathrm{CO}_{2}$ analytical standard gases (Supelco-Sigma Aldrich, St. Louis, MO, USA).

\section{Results and Discussion}

\subsection{Algal biomass characterization and theoretical methane yield}

The compositions of WA and LEA are shown in Table 2. The fraction of ash is below $10 \%$ for both WA and LEA. The concentrations of all parameters, except volatile solids (VS) and hydrogen, were higher in the LEA than in WA. A. protothecoides biomass generated by a sequential phototrophic-heterotrophic process has very high lipid content of up to $60 \%$. Lipids have very low ash content and abundant hydrogen. Therefore, extraction of lipids causes an increase in ash and reduction in hydrogen concentration in the LEA. In contrast, the concentrations of all other elements increased substantially in the LEA vs. WA as the result of lipid extraction. Lipids, more specifically neutral lipids, have low 
contents of $\mathrm{O}, \mathrm{N}, \mathrm{P}$ and $\mathrm{S}$. Moreover, these nutrients and trace elements are usually components of polar or charged compounds or present in the biomass in ionic forms. Most of them do not co-extract with the lipid fraction and therefore become more concentrated in the LEA. Therefore, it is not surprising that the content of most trace metals and metalloids in LEA is nearly 2.8-5 times higher compared to the original WA. The elevation in these elements is slightly higher than that anticipated (up to 2.5 times) due solely to removal of lipids. These unexpectedly higher values may be the result of contamination with metals during the bead milling and acetone/hexane extraction processes. In support of this explanation is the concentrations of $\mathrm{Zn}$ and $\mathrm{Ni}$ increased in the biomass approximately thirty times in comparison to the levels in the WA.

The theoretically calculated maxima of biogas and methane yields are shown in Table 3. As shown earlier, the type of algal biomass and substrate composition has a major impact on the methane produced during anaerobic digestion (Bohutskyi et al., 2014a). The WA, containing high concentrations of energy-rich lipids, had higher biogas potential and methane content. However, the LEA was more favorable for anaerobic digestion due to higher protein content and therefore a lower $\mathrm{C}: \mathrm{N}$ ratio. In contrast, the anaerobic digestion of the lipid-rich WA may be limited in nitrogen content since the optimal carbon to nitrogen ratio for AD is in the range from 15:1 to 25:1 (Eder \& Heinz, 2006).

\subsection{Effect of organic loading rate (OLR) and hydraulic retention time (HRT) on anaerobic digestion of lipid extracted algal residues (LEA)}

The $A$. protothecoides LEA was subjected to AD in a semi-continuous completely mixed bioreactor. The efficiency of conversion was investigated at four different operational regimes applied sequentially by varying the OLR and hydraulic retention times (HRTs) 
(Table 1). First, the bioreactor was operated at an OLR $1.0 \mathrm{gVS} / \mathrm{L}-$ day and HRT 20 days. Second, the OLR was increased to $2.0 \mathrm{gVS} / \mathrm{L}$-day while maintaining the same HRT of 20 days. Third, the HRT was extended to 40 days but the OLR was reduced to $1.0 \mathrm{gVS} / \mathrm{L}-$ day. Finally the OLR was increased to $1.5 \mathrm{gVS} / \mathrm{L}$-day for an HRT of 40 days. The volumetric and specific biogas production rates at these different operational parameters are shown in Figures $1 \mathrm{~A}$ and $1 \mathrm{~B}$, respectively. The $\mathrm{AD}$ process was stable for at least 20-30 days in a row under certain conditions. However, in every run except the run with OLR $1.0 \mathrm{gVS} / \mathrm{L}$ day and HRT 40 days, the conversion process was disrupted at some point. The reduction in biogas production rate was observed together with a drop in $\mathrm{pH}$ from about neutral $\mathrm{pH}$ 7.0-7.2) to acidic values ( $\mathrm{pH}$ 4.7-5.5). Interestingly, $\mathrm{pH}$ neutralization by $\mathrm{NaOH}$ addition effectively restored the process under the OLR $1.0 \mathrm{gVS} / \mathrm{L}$-day, HRT 20 day treatment but it was not beneficial under the OLR $2.0 \mathrm{gVS} / \mathrm{L}$-day, HRT 20 day treatment. Various factors can cause instability of the $\mathrm{AD}$ process, including fluctuation in operational parameters (temperature, $\mathrm{pH}, \mathrm{OLR}$, redox potential or gas leakage) or the presence of inhibitory compounds (ammonia, sulfide, organic compounds, light or heavy metals) (Chen et al., 2008). The presence of solvent residues with the wet algal biomass feed to the bioreactor seems to be the most probable reason for process interruptions in the current study. The recovery of the anaerobic organisms at OLR $1.0 \mathrm{gVS} / \mathrm{L}$-day, HRT 20 days and robust performance at OLR $1.0 \mathrm{gVS} / \mathrm{L}$-day, HRT 40 days could be explained either by acclimation of the anaerobic organisms or partial degradation of the solvent residues in the bioreactor. However, greater inhibition of the anaerobes was observed at the higher OLR 2.0 gVS/L-day and associated higher solvent dose. While certain anaerobic organisms can degrade both alkanes (such as n-hexane (Aeckersberg et al., 1991)) and ketones (such as 
acetone (Zhang et al., 2011)) so that they may be degraded by anaerobic organisms, it has been shown that both alkanes and ketones can be toxic to AD microbial consortia, especially to acetoclastic methanogens, and inhibit biogas production (Hayward \& Lau, 1989; Playne \& Smith, 1983; Zhang et al., 2011). Therefore, the solvent toxicity levels need to be understood or its residues removed from LEA in order to avoid or mitigate negative impact on methane production. Preliminary LEA drying could be one of the methods. Zhao et al. reported the toxicity effect after utilizing chloroform/methanol (2:1, $\mathrm{v} / \mathrm{v})$ for extraction but no inhibition when hexane/isopropanol $(3: 2, \mathrm{v} / \mathrm{v})$ or acetone/dichloromethane $(1: 1, \mathrm{v} / \mathrm{v})$ were used. They utilized LEA subjected to air and oven drying prior to $\mathrm{AD}$ (Zhao et al., 2014). The oven drying process could effectively remove or reduce significant amounts of residual solvent but needs to be done in a cost effective manner to be relevant to production of algal biofuels. Even more beneficial from an economical and environmental prospective could be application of the alterative extraction methods that do not utilize solvents such as reverse micelle or supercritical $\mathrm{CO}_{2}$ extraction techniques. In addition, processing of microalgae at supercritical condition may increase biodegradability and methane production through disintegration of the algal cell wall and hydrolysis of biomass polymers into compounds readily available for anaerobic bacteria (Hernandez et al., 2014).

The average biogas and methane production rates are shown in Figure 2. While increasing the HRT from 20 to 40 days at an OLR of $1.0 \mathrm{gVS} / \mathrm{L}$-day slightly improved the specific biogas and methane production rates (Figure $2 \mathrm{~A}$ ), the volumetric gas production rate at HRT 20 and an OLR $1.0 \mathrm{gVS} / \mathrm{L}$-day is more than $50 \%$ higher compared to other runs (Figure $2 \mathrm{~B}$ ). Interestingly, raising the OLR from 1.0 to $1.5 \mathrm{gVS} / \mathrm{L}$-day with HRT 40 
days did not enhance the volumetric gas production rate but substantially decreased specific gas production rate. The average methane content in biogas was $50-52 \%$ at all operational parameters except an OLR of $1.5 \mathrm{gVS} / \mathrm{L}$-day and HRT 40 when methane content decreased to $47 \%$. This relatively low methane content is slightly lower but in agreement with the theoretically predicted value (Table 3) and reflects rich carbohydrate content in the LEA. As was shown before, carbohydrates have the lowest methane potential compared to proteins and lipids (Bohutskyi et al., 2014a). The observed biogas and methane yields were nearly $45-55 \%$ lower than the theoretically calculated values (Table 4). The highest ratio was detected for the OLR $1.0 \mathrm{gVS} / \mathrm{L}$-day and lowest for the OLR of $1.5 \mathrm{gVS} / \mathrm{L}$-day (both at HRT 40). Interestingly, VSR rates (Table 4) followed the same trend but were about $15 \%$ higher than the ratio of observed to theoretical biogas production rates. An explanation for this difference is that the Buswell empirical formula (Equation 1) may overestimate the methane and biogas potential because it does not account for organic carbon assimilated into microbial cells. Additionally, it may be evidence of minor gas leakage. In general, the measured specific methane production 0.18 $0.25 \mathrm{~L} / \mathrm{gVS}$ is similar or slightly lower than the previously reported methane yields, which were in the range 0.2-0.35 L/gVS (Bohutskyi et al., 2014b; Hernandez et al., 2014; Zhao et al., 2014). However, the higher values were collected by applying biomethane potential procedure using defined anaerobic medium amended with nutrients, vitamins, $\mathrm{pH}$, redox buffers and providing long residence time at batch conditions.

Comparison of the maximum theoretical amount of energy that can be produced to actual production of energy as biodiesel and methane achieved in the current study as well as that of a projected optimistic scenario is shown in Figure 3. First, the important 
observation is that conversion of whole biomass into methane alone through $\mathrm{AD}$ is more energy favorable based on the theoretical maximum than production of biodiesel alone. The projected benefit for methane over biodiesel is $43 \%, 9 \%$ and $20 \%$ higher for theoretical maximum, observed and optimistic energy production scenarios, respectively. $\mathrm{AD}$ converts all fractions of biomass (lipids, proteins, and carbohydrates) into methane and minimizes generation of residues. However, an integrated biodiesel and methane process generates the highest amount of energy with an increase of $46 \%, 31 \%$ and $40 \%$ in total energy production over biodiesel in theoretical maximum, observed and optimistic scenarios, respectively. Moreover, production of liquid fuel is more advantageous from an economic point of view. Another important observation from these data is that the observed energy recovered is substantially lower than the theoretical maximum. The theoretical maximum scenario presumes conversion of all lipids into biofuel. However, only the easily convertible TAGs fraction was processed into biodiesel under the current scenario. The decrease in energy yield for AD is even more dramatic and caused mostly by incomplete conversion of algal biomass into biogas. As discussed earlier, the biodegradability may be limited by cell wall and algal protein recalcitrance. The methane production was significantly lower than maximum predicted methane yield (Table 4). Both these factors caused $40 \%$ and $32 \%$ reductions, respectively, in energy yield under the current scenario. Future research (included in the optimistic prospective scenario) should focus on optimization of technology to convert all lipid fractions (including polar lipids and waxes) into fatty acid methyl esters to maximize fuel yield. In addition, the AD efficiency and methane yield have to be improved from observed $50 \%$ to at least $80 \%$. While our lab showed previously that thermal and thermo-chemical pretreatments can 
increase methane yield from Nannochloropsis biomass (Bohutskyi et al., 2014a), it would be beneficial to develop less energy consuming and more environmentally friendly pretreatment methods. Finally, it was shown that triacylglycerol by-products could be used as AD substrate enhancing energy yield from algal biomass even further (Siles Lopez et al., 2009). Implementation of these advances could allow increasing the energy production by nearly $30 \%$ from $20 \mathrm{MJ} / \mathrm{kgVS}$ achieved in the current study to $26 \mathrm{MJ} / \mathrm{kgVS}$ if all lipid fractions are processed into biodiesel and LEA together with other by-products are effectively converted into methane through anaerobic digestion.

\subsection{Nutrient recovery and availability for recycling}

The concentration of the elements in the liquid fraction of the AD effluent was determined in order to determine the fraction released from the LEA which became available for recycling to the algal cultivation stage. The content of soluble macro- and micronutrients at different operational conditions is shown in Figure 4.

The concentration of the soluble nitrogen increased with increasing the OLR from 1 to $2 \mathrm{gVS} / \mathrm{L}$-day during Run 2 (Figures $4 \mathrm{~A}$ ). Most of the soluble nitrogen was measured as ammonia. Nitrogenous compounds, mostly proteins, present in the LEA were biologically converted by anaerobic microorganisms into biogas and soluble ammonia nitrogen. Additionally, the extension of the HRT from 20 to 40 days resulted in minor increases in the concentration of soluble nitrogen reflecting the enhancement of biological degradation of proteins with increasing HRT. These data are in agreement with the biogas and methane production discussed in the previous section. However, increasing the OLR from 1 to 1.5 gVS/L-day at HRT 40 days (Run 4) didn't result in further elevation of the soluble nitrogen concentration, possibly due to process inhibition considered earlier. The soluble 
nitrogen represented only up to $40 \%$ of the nitrogen supplied with LEA (Figure 5 A). The rest of the nitrogen was likely trapped in recalcitrant organic matter, assimilated by the anaerobic microorganisms or precipitated as struvite $\left(\mathrm{MgNH}_{4} \mathrm{PO}_{4}{ }_{6} \mathrm{H}_{2} \mathrm{O}\right)$. It was reported earlier that a significant fraction of the Chlorella's cell wall may be composed of nitrogenous bio-polymers and extraordinary robust sporopollenin components as part of trilaminar wall structure (Atkinson et al., 1972; Burczyk et al., 1999). Moreover, Takeda showed that a chitin-protein complex, resistant to enzymatic digestion (cellulase, chitinase, and glusulase) and acid hydrolysis, made up to $40 \%$ of the cell wall in some Chlorella protothecoides species (Conte \& Pore, 1973). Similarly, degradation of nearly $30 \%$ of the particulate protein was observed during anaerobic digestion of bacterial biomass (ㅁougrier et al., 2007). The precipitation as struvite is most likely only responsible for a small amount of ammonia loss since the $\mathrm{pH} \sim 7$ is not favorable for struvite formation (Nelson et al., 2003). Therefore, the presence of these bio-polymers might be partially responsible for relatively low level of nitrogen recovery.

The concentration of soluble phosphorus increased along with increasing of OLR and HRT (Figure 4 B). Orthophosphate represented the major fraction of the soluble phosphorus. However, the fraction of orthophosphate in total soluble $\mathrm{P}$ was reduced at higher OLRs and especially during Run 4. The phosphorus in LEA feedstock is present mostly as orthophosphate and organic phosphorus compounds such as phosphorylated proteins, phospholipids, phosphosaccharides (e.g. ATP and phosphoglycans) and nucleic acids. Organic $\mathrm{P}$ is mineralized to orthophosphate during anaerobic digestion and might be precipitated as metal phosphates or struvite as discussed above. Interestingly, the amount of P released from the LEA that remained soluble varied from 30 to $60 \%$ of total LEA 
phosphorus. The soluble fraction increased when more of the $\mathrm{P}$ is present in the form of organic phosphorus with lower reactivity compared to orthophosphate. These values are somewhat higher than the previously reported value for soluble orthophosphate fraction, nearly $20 \%$ at similar phosphorus load for AD treating sewage sludge (Carliell \& Wheatley, 1997). This difference might be due to a lower concentration of phosphorus and metals in LEA.

The remaining macro- and micronutrients could be classified into several groups based on the concentration response pattern to changes in the $\mathrm{AD}$ operation conditions. The first and largest group includes $\mathrm{Mn}, \mathrm{Zn}, \mathrm{Fe}, \mathrm{Co}, \mathrm{Ni}, \mathrm{Cr}, \mathrm{As}, \mathrm{Tl}, \mathrm{Cd}, \mathrm{Pb}, \mathrm{Ag}$, In and Cs. The soluble concentration of these elements didn't vary and remained either constant or changed insignificantly at all operational conditions, potentially due to limited solubility of these elements in the aqueous phase. The only exception was a spike in the concentration of $\mathrm{Zn}, \mathrm{Co}, \mathrm{Ni}, \mathrm{Cr}, \mathrm{Cd}, \mathrm{Pb}$, and $\mathrm{Ag}$ at an OLR $1.5 \mathrm{gVS} / \mathrm{L}$-day and HRT 40 days. One possible reason is the accumulation of the organic compounds in the soluble phase due to inhibition of the mineralization process. The decrease in $\mathrm{pH}$ value indicates a rising content of short chain fatty acids (SCFA) because of methanogen inhibition (discussed in previous subsection). Additionally, the amount of polyphosphates in the medium increased too (Figure 4 B). Both, SCFA and polyphosphates are soluble and positively charged. They may serve as organic ligands stabilizing positively charged metal ions in the solution. A similar elevation in $\mathrm{Cr}, \mathrm{Zn}, \mathrm{Ni}$ and $\mathrm{Co}$ concentration in the inhibited $\mathrm{AD}$ bioreactor with the buildup of polyphosphate content was reported earlier (Carliell-Marquet \& Wheatley, 2002). The second group of elements includes $\mathrm{Mg}, \mathrm{Ca}, \mathrm{S}, \mathrm{B}, \mathrm{Rb}$ and $\mathrm{Sr}$. The concentration of these elements increased with increasing OLR. Interestingly, the extension of the HRT 
from 20 to 40 days negatively impacted the soluble concentrations of S and Sr. One possible explanation could be their slower precipitation kinetics compared to the elements from the first group. Finally, a third group is comprised of $\mathrm{Mo}, \mathrm{Cr}, \mathrm{Ni}, \mathrm{Be}, \mathrm{Ba}$, and $\mathrm{V}$. Their soluble concentrations decreased as the OLR and HRT were increased. Most metals precipitate as $\mathrm{Fe} / \mathrm{Mn}$ oxides and sulfides (Dabrowska, 2011) leading to stronger precipitation when more $\mathrm{Fe} / \mathrm{Mn}$ and sulfides are present in the $\mathrm{AD}$. In addition, adsorption and co-precipitation on newly generated sulfide precipitates may be an important mechanism for limiting the solubility of other elements.

Only a few elements, including $\mathrm{Mg}, \mathrm{Ca}$ and $\mathrm{S}$, in addition to $\mathrm{N}$ and $\mathrm{P}$ showed a strong potential for recycling with the liquid fraction of the $\mathrm{AD}$ effluent. Their soluble fraction varied between 20 and $50 \%$ depending on the operational conditions. These elements are essential for microalgae. Along with other functions magnesium serves as a stabilization and coordination factor in various enzymes and light-harvesting pigments including chlorophyll, it is a mediator in many signaling pathways and involved in gene transcription and translation of genes (Wilkinson et al., 1990). Sulfur is a component of many amino acids and one of the key parts in electron transport within the photosynthetic machinery ( binding proteins (Allan \& Trewavas, 1987). The soluble fractions of Mn and Fe were between $10-25 \%$ and $4-15 \%$, respectively. Manganese is another trace element especially important to photosynthetic organisms, such as microalgae, since it is a component of the water splitting polynuclear cluster in photosystem II (Raven et al., 1999). Only up to 5\% of $\mathrm{Cu}, \mathrm{Zn}$, Mo and Co could be recovered from the LEA with digestate for potential recycling. However, these elements are also essential for augmented algal growth. Copper 
is part of the photosynthetic and mitochondrial electron transport chain and zinc serves as a co-factor in various metalloenzymes, such as in carbonic anhydrase necessary for efficient hydration of dissolved $\mathrm{CO}_{2}$ in solution (Raven et al., 1999). Molybdenum and cobalt are also important co-factors or parts of essential organometallic compounds such as nitrate reductase (Fernandez \& Cardenas, 1981) and vitamin $\mathrm{B}_{12}$ (Banerjee \& Ragsdale, 2003), respectively. It would be beneficial to increase the soluble fraction of these elements in the $\mathrm{AD}$ effluent for more efficient recovery. Importantly, up to $30-50 \%$ of the potentially toxic elements, including $\mathrm{As}, \mathrm{Tl}, \mathrm{Cd}, \mathrm{Pb}, \mathrm{Ba}, \mathrm{Be}$ and $\mathrm{Cs}$, remain soluble at certain operating conditions. In contrast to nutrients discussed previously, it would be advantageous to reduce their soluble fraction in the $\mathrm{AD}$ effluent since there is a potential for a build up in their concentrations in the algal production system if continuous recycling is routinely used. Moreover, further studies on the potential release of these pollutants into the environment with the solid fraction of the AD effluent would be highly relevant for a more complete understanding of the environmental sustainability of emerging algal biofuel technologies.

\subsection{Economic and sustainability effects from the nutrient recycling}

The economical importance of the nutrient recycling from $\mathrm{AD}$ effluent and its significance for process sustainability were predicted by estimating their amounts and costs per gallon of the generated biodiesel. Then, the nutrient amounts for scaling algal biofuel production to $10 \%$ of liquid fuel consumption in the U.S. (29 billion gallons per year, BGY) were estimated in order to evaluate the impact of nutrient recycling on sustainability of algal biofuel production. These calculations account only for nutrients supplied and assimilated by microalgae during the cultivation process leaving out unutilized nutrients remaining in 
the spent growth medium or used for algal growth during heterotrophic conditions with glucose. The first scenario without nutrient recycling was compared to the second scenario that included nutrient recovery through recycling of the AD effluent after LEA conversion.

The costs of essential macro- and micronutrients per gallon of the produced algal biodiesel are shown in Figure 6 A. Even without recycling the total nutrient cost represents $\$ 0.165$ per gallon of algal biodiesel or $4-5.5 \%$ of the desired biofuel price of $\$ 3-4$ per gallon. Remarkably, the costs of nitrogen, phosphorus and potassium $(\$ 0.089, \$ 0.034$ and $\$ 0.03$ per gallon respectively) represent the major fraction of the overall nutrient cost in algal biomass during cultivation. The contribution from all other nutrients is slightly higher than $\$ 0.01$ per gallon. However, scaling algal biofuel production to $10 \%$ of the U.S. liquid fuel consumption is a challenge since it would require enormous amounts of fertilizers, comparable to the current consumption of these elements for the total agricultural needs in the U.S. (Figure 6 B). The demand for nitrogen, phosphorus, potassium and magnesium fertilizers would increase by nearly $15-25 \%$ compared to their current use in agriculture. Significant elevation of the demand for fertilizers like nitrogen, phosphorus and potassium can boost their price and therefore the prices for all agricultural products, including food and even produced biodiesel. Notably, recycling of AD effluent could potentially reduce the nutrient expenditure by $45 \%$ to $\$ 0.092$ per gallon of algal biodiesel. But most importantly, implementation of nutrient recycling could decrease the requirement for nitrogen, phosphorus, potassium and magnesium fertilizers for algal cultivation to nearly $6-16 \%$ of current consumption of these elements for agricultural needs in the U.S. (Figure $6 \mathrm{~B}$ ). Further optimization of AD process and nutrient recovery from AD effluent could further enhance process efficiency and sustainability and the associated costs. 


\section{Conclusions}

The methane production from lipid-extracted algal residues (LEA) was up to $0.25 \mathrm{~L} / \mathrm{gVS}$ increasing the energy yield from algal biomass by more than 30\%. Additionally, up to 40 $60 \%$ of $\mathrm{N}$ and $\mathrm{P}, 30-60 \%$ of $\mathrm{Mg}, \mathrm{Ca}$, and $\mathrm{S}$, and $15-25 \%$ of $\mathrm{Mn}$ and Fe present in the LEA could be available for recycling with $\mathrm{AD}$ effluent. As N, P and K represent the main cost of nutrients supplied to a cultivation system, their recovery from LEA and recycling can reduce fertilizer costs by $45 \%$ and improve the process sustainability especially for a scaled-up process.

\section{Acknowledgements}

This project was financially supported by the U.S. NSF CBET Program (Grant No.1236691 to JHU), U.S. DOE CCS Program (Grant No.DE-FE0001888 to Phycal) and The Bureau of Education and Cultural Affairs of U.S. Department of State through an International Fulbright Science and Technology Award to Pavlo Bohutskyi. The authors are also grateful to Dr. George Oyler and Julian Rosenberg (Clean Green Chesapeake) for providing bioreactor equipment for the current study. 


\section{References}

[1] Aeckersberg, F., Bak, F., Widdel, F. 1991. Anaerobic oxidation of saturated hydrocarbons to $\mathrm{CO}_{2}$ by a new type of sulfate-reducing bacterium. Arch. Microbiol., 156 (1991), 5-14.

[2] Allan, E.F., Trewavas, A.J. 1987. The role of calcium in metabolic control. in: The biochemistry of plants, (Eds.) P.K. Stumpf, E.E. Conn, Vol. 12, Academic Press. San Diego, USA.

[3] Atkinson, A.W., Gunning, B.E.S., John, P.C.L. 1972. Sporopollenin in the cell wall of Chlorella and other algae: Ultrastructure, chemistry, and incorporation of 14Cacetate, studied in synchronous cultures. Planta, 107 (1972), 1-32.

[4] Banerjee, R., Ragsdale, S.W. 2003. The many faces of vitamin $\mathrm{B}_{12}$ : catalysis by cobalamin-dependent enzymes. Annu. Rev. Biochem., 72 (2003), 209-247.

[5] Bohutskyi, P., Betenbaugh, M.J., Bouwer, E.J. 2014a. The effects of alternative pretreatment strategies on anaerobic digestion and methane production from different algal strains. Bioresour. Technol., 155 (2014), 366-372.

[6] Bohutskyi, P., Bouwer, E. 2013. Biogas Production from Algae and Cyanobacteria Through Anaerobic Digestion: A Review, Analysis, and Research Needs. in: Advanced Biofuels and Bioproducts, (Ed.) J.W. Lee, Springer New York, pp. 873975.

[7] Bohutskyi, P., Kula, T., Kessler, B., Hong, Y., Bouwer, E., Betenbaugh, M., Allnutt, F.C.T. 2014b. Mixed Trophic State Production Process for Microalgal Biomass with High Lipid Content for Generating Biodiesel and Biogas. Bioenergy Res., 7 (2014), 1174-1185.

[8] Bohutskyi, P., Liu, K., Kessler, B., Kula, T., Hong, Y., Bouwer, E., Betenbaugh, M., Allnutt, F.C.T. 2014c. Mineral and non-carbon nutrient utilization and recovery during sequential phototrophic-heterotrophic growth of lipid-rich algae. Appl. Microbiol. Biotechnol., 98 (2014), 5261-73.

[9] Bougrier, C., Delgenès, J.P., Carrère, H. 2007. Impacts of thermal pre-treatments on the semi-continuous anaerobic digestion of waste activated sludge. Biochem. Eng. J., 34 (2007), 20-27.

[10] Burczyk, J., Smietana, B., Terminska-Pabis, K., Zych, M., Kowalowski, P. 1999. Comparison of nitrogen content amino acid composition and glucosamine content of cell walls of various Chlorococcalean algae. Phytochem., 51 (1999), 491-497.

[11] Buswell, A.M., Mueller, H.F. 1952. Mechanism of Methane Fermentation. Ind. Eng. Chem., 44 (1952), 550-552.

[12] Carliell, C., Wheatley, A. 1997. Metal and phosphate speciation during anaerobic digestion of phosphorus rich sludge. Water Sci. Technol., 36 (1997), 191-200.

[13] Carliell-Marquet, C.M., Wheatley, A.D. 2002. Measuring metal and phosphorus speciation in P-rich anaerobic digesters. Water Sci. Technol., 45 (2002), 305-12.

[14] Chen, Y., Cheng, J.J., Creamer, K.S. 2008. Inhibition of anaerobic digestion process: A review. Bioresour. Technol., 99 (2008), 4044-4064.

[15] Conte, M.V., Pore, R.S. 1973. Taxonomic implications of Prototheca and Chlorella cell wall polysaccharide characterization. Arch. Mikrobiol., 92 (1973), 227-233.

[16] Dabrowska, L. 2011. Speciation of heavy metals in sewage sludge after mesophilic and thermophilic anaerobic digestion. Chem. Pap., 66 (2011), 598-606. 
[17] Eaton, A.D., Franson, M.A.H. 2005. Standard Methods for the Examination of Water \& Wastewater. 21 ed. APHA, AWWA, and WEF, New York.

[18] Eder, B., Heinz, S. 2006. Biogas Praxis: Grundlagen, Planung, Anlagenbau, Beispiele, Wirtschaftlichkeit. Ökobuch Verlag u. Versand, Staufen, Deutschland

[19] Fernandez, E., Cardenas, J. 1981. Occurrence of xanthine dehydrogenase in Chlamydomonas reinhardii: A common cofactor shared by xanthine dehydrogenase and nitrate reductase. Planta, 153 (1981), 254-257.

[20] Gao, Y., Yang, M., Wang, C. 2013. Nutrient deprivation enhances lipid content in marine microalgae. Bioresour. Technol., 147 (2013), 484-491.

[21] Haehnel, W. 1984. Photosynthetic Electron Transport in Higher Plants. Annual Review of Plant Physiol., 35 (1984), 659-693.

[22] Hayward, G., Lau, I. 1989. Toxicity of organic solvents to fatty acid forming bacteria. Can. J. Chem. Eng., 67 (1984), 157-161.

[23] Hernandez, D., Solana, M., Riano, B., Garcia-Gonzalez, M.C., Bertucco, A. 2014. Biofuels from microalgae: Lipid extraction and methane production from the residual biomass in a biorefinery approach. Bioresour. Technol., 170 (2014), 370378.

[24] Nelson, N.O., Mikkelsen, R.L., Hesterberg, D.L. 2003. Struvite precipitation in anaerobic swine lagoon liquid: effect of $\mathrm{pH}$ and $\mathrm{Mg}: \mathrm{P}$ ratio and determination of rate constant. Bioresour. Technol., 89 (2003), 229-236.

[25] Pate, R., Klise, G., Wu, B. 2011. Resource demand implications for U.S. algae biofuels production scale-up. Appl. Energy, 88 (2011), 3377-3388.

[26] Playne, M.J., Smith, B.R. 1983. Toxicity of organic extraction reagents to anaerobic bacteria. Biotechnol. Bioeng., 25 (1983), 1251-1265.

[27] Raven, J.A., Evans, M.C.W., Korb, R.E. 1999. The role of trace metals in photosynthetic electron transport in $\mathrm{O}_{2}$-evolving organisms. Photosynth. Res., 60 (1999), 111-150.

[28] Schenk, P.M., Thomas-Hall, S.R., Stephens, E., Marx, U.C., Mussgnug, J.H., Posten, C., Kruse, O., Hankamer, B. 2008. Second Generation Biofuels: High-Efficiency Microalgae for Biodiesel Production. Bioenergy Res., 1 (2008), 20-43.

[29] Siles Lopez, J.A., Martin Santos, M.d.l.A., Chica Perez, A.F., Martín Martin, A. 2009. Anaerobic digestion of glycerol derived from biodiesel manufacturing. Bioresour. Technol., 100 (2009), 5609-5615.

[30] U.S. EIA. 2013. Monthly Energy Review, September 2013, DOE/EIA-0035(2013/09). Projections: AEO2014 National Energy Modeling System, run REF2014.D102413A. . U.S. EIA.

[31] U.S. GS. 2014. Mineral commodity summaries 2014. U.S. GS.

[32] Wilkinson, S., Welch, R., Mayland, H., Grunes, D. 1990. Magnesium in plants: uptake, distribution, function, and utilization by man and animals. in: Met. Ions Biol. Syst., (Eds.) H. Siegel, A. Siege, Vol. 26, Marcel Dekker, Inc. New York, pp. 33-56.

[33] Yu, W.-L., Ansari, W., Schoepp, N.G., Hannon, M.J., Mayfield, S.P., Burkart, M.D. 2011. Modifications of the metabolic pathways of lipid and triacylglycerol production in microalgae. Microb. Cell Fact., 10 (2011), 91. 
[34] Zhang, J., Wei, Y., Xiao, W., Zhou, Z., Yan, X. 2011. Performance and spatial community succession of an anaerobic baffled reactor treating acetone-butanolethanol fermentation wastewater. Bioresour. Technol., 102 (2011), 7407-7414.

[35] Zhao, B., Ma, J., Zhao, Q., Laurens, L., Jarvis, E., Chen, S., Frear, C. 2014. Efficient anaerobic digestion of whole microalgae and lipid-extracted microalgae residues for methane energy production. Bioresour. Technol., 161 (2014), 423-430. 


\section{List of Tables}

Table 1. Bioreactor operational parameters

Table 2. Physicochemical composition of Auxenochlorella protothecoides whole algae (WA) and lipid-extracted residues (LEA) as percent of dry weight

Table 3. Theoretically calculated maximum yields of biogas, methane, ammonia and hydrogen sulfide per gram of substrate volatile solids (VS)

Table 4. Observed to theoretical methane production ratio and volatile solids reduction (VSR) depending from the operational parameters

\section{List of Figures}

Figure 1. Average volumetric (A) and specific (B) biogas and methane production rates at four different operational regimes.

Figure 2. Average volumetric (A) and specific (B) biogas and methane production rates at different operational parameters. Error bars represent the standard deviation among daily gas productions during the stable period.

Figure 3. Theoretical maximum, current and projected optimistic scenarios of energy production per $1 \mathrm{kgVS}$ of algal biomass (total lipids $57 \%$, TAGs $45 \%$ of dry weight).

Figure 4. Concentration of elements in the soluble fraction of the digestate at different operational parameters.

Figure 5. Fraction of elements concentrated in the soluble fraction of the digestate at different operational parameters.

Figure 6. (A) Cost of nutrients required for production one gallon of algal biodiesel. (B) Nutrient amount required for generation of algal biodiesel equal to $10 \%$ of the current liquid fuel consumption in the U.S., as part of their current use in agriculture. 
Table 1. Bioreactor operational parameters

\begin{tabular}{cccc} 
Run & $\begin{array}{c}\text { Feed, } \\
\mathrm{gVS} / \mathrm{L}\end{array}$ & $\begin{array}{c}\text { HRT, } \\
\text { days }\end{array}$ & $\begin{array}{c}\text { OLR, } \\
\text { gVS/L-day }\end{array}$ \\
\hline 1 & $19.4 \pm 1.2$ & 20 & $0.97 \pm 0.06$ \\
2 & $40.9 \pm 1.5$ & 20 & $2.05 \pm 0.08$ \\
3 & $38.0 \pm 2.0$ & 40 & $0.95 \pm 0.05$ \\
4 & $61.6 \pm 2.2$ & 40 & $1.54 \pm 0.06$ \\
\hline
\end{tabular}


Table 2. Physicochemical composition of Auxenochlorella protothecoides whole algae (WA) and lipid-extracted residues (LEA) as percent of dry weight

\begin{tabular}{|c|c|c|c|c|c|}
\hline Parameter & $\mathrm{WA}^{\mathrm{a}}$ & LEA $^{\mathrm{b}}$ & Parameter & WA & LEA \\
\hline Ash & $4 \pm 1$ & $6 \pm 2$ & Aluminum & $0.6 \times 10^{-3}$ & $2.4 \times 10^{-3}$ \\
\hline $\mathrm{VS}^{\mathrm{c}}$ & $96 \pm 1$ & $94 \pm 2$ & Tellurium & $0.12 \times 10^{-3}$ & $0.34 \times 10^{-3}$ \\
\hline Total lipid & 57 & $\mathrm{n} / \mathrm{a}^{\mathrm{d}}$ & Molybdenum & $0.1 \times 10^{-3}$ & $0.28 \times 10^{-3}$ \\
\hline $\mathrm{TAGs}^{\mathrm{e}}$ & 45 & $\mathrm{n} / \mathrm{a}$ & Cobalt & $0.027 \times 10^{-3}$ & $0.13 \times 10^{-3}$ \\
\hline Carbohydrates & 33 & 75 & Boron & $0.03 \times 10^{-3}$ & $0.55 \times 10^{-3}$ \\
\hline Crude protein & 6 & 14 & Chromium & $0.07 \times 10^{-3}$ & $0.22 \times 10^{-3}$ \\
\hline Carbon & 59 & 44.4 & Rubidium & $0.06 \times 10^{-3}$ & $2.9 \times 10^{-3}$ \\
\hline Oxygen & 26 & 39 & Strontium & $0.04 \times 10^{-3}$ & $2.4 \times 10^{-3}$ \\
\hline Hydrogen & 9.6 & 7.1 & Barium & $0.02 \times 10^{-3}$ & $0.07 \times 10^{-3}$ \\
\hline Nitrogen & 1.5 & 2.3 & Nickel & $0.02 \times 10^{-3}$ & $0.68 \times 10^{-3}$ \\
\hline Phosphorus & 0.4 & 1.2 & Vanadium & $0.02 \times 10^{-3}$ & $0.11 \times 10^{-3}$ \\
\hline Calcium & 0.15 & 0.42 & Silver & $0.016 \times 10^{-3}$ & $0.08 \times 10^{-3}$ \\
\hline Sulfur & 0.07 & 0.185 & Arsenic & $0.01 \times 10^{-3}$ & $0.05 \times 10^{-3}$ \\
\hline Magnesium & 0.04 & 0.11 & Indium & $0.004 \times 10^{-3}$ & $0.024 \times 10^{-3}$ \\
\hline Iron & 0.012 & 0.043 & Lead & $0.005 \times 10^{-3}$ & $0.024 \times 10^{-3}$ \\
\hline Zinc & $0.78 \times 10^{-3}$ & $22 \times 10^{-3}$ & Cadmium & $0.008 \times 10^{-3}$ & $0.03 \times 10^{-3}$ \\
\hline Copper & $0.65 \times 10^{-3}$ & $2 \times 10^{-3}$ & Beryllium & $0.007 \times 10^{-3}$ & $0.01 \times 10^{-3}$ \\
\hline Manganese & $0.8 \times 10^{-3}$ & $4.5 \times 10^{-3}$ & Cesium & $0.002 \times 10^{-3}$ & $0.006 \times 10^{-3}$ \\
\hline
\end{tabular}


Table 3. Theoretically calculated maximum yields of biogas, methane, ammonia and hydrogen sulfide per gram of substrate volatile solids (VS)

Theoretically Calculated Values

\begin{tabular}{cccccccc}
$\begin{array}{c}\text { Substrate type and } \\
\text { chemical formula }\end{array}$ & $\begin{array}{c}\text { Carbon } \\
\text { oxidation } \\
\text { state }\end{array}$ & $\begin{array}{c}\mathrm{C}: \mathrm{N} \\
(\mathrm{wt} / \mathrm{wt})\end{array}$ & $\begin{array}{c}\text { biogas } \\
\mathrm{L} / \mathrm{gVS}\end{array}$ & $\begin{array}{c}\mathrm{CH}_{4} \\
\mathrm{~L} / \mathrm{gVS}\end{array}$ & $\mathrm{CH}_{4}$ & $\begin{array}{c}\mathrm{NH}_{3} \\
\mathrm{mgN} /\end{array}$ & $\mathrm{H}_{2} \mathrm{~S}$ \\
$\mathrm{gVS}$ & $\mathrm{gVS}$ \\
\hline
\end{tabular}

\begin{tabular}{lccccccc}
\hline A. protothecoides (WA) & -1.23 & 38.5 & 1.15 & 0.75 & 65 & 16.1 & 0.7 \\
$\mathrm{C}_{2258} \mathrm{H}_{4383} \mathrm{O}_{733} \mathrm{~N}_{50.4} \mathrm{~S}$ & & & & & & & \\
$\begin{array}{l}\text { A. protothecoides (LEA) } \\
\mathrm{C}_{641} \mathrm{H}_{1227} \mathrm{O}_{433} \mathrm{~N}_{28.6} \mathrm{~S}\end{array}$ & -0.43 & 19.2 & 0.88 & 0.48 & 55 & 24.6 & 2.0 \\
$\begin{array}{l}\text { Glycerol } \\
\mathrm{C}_{3} \mathrm{H}_{8} \mathrm{O}_{3}\end{array}$ & -0.67 & $\mathrm{n} / \mathrm{a}$ & 0.73 & 0.43 & 58 & $\mathrm{n} / \mathrm{a}$ & $\mathrm{n} / \mathrm{a}$ \\
\hline
\end{tabular}


Table 4. Observed to theoretical methane production ratio and volatile solids reduction (VSR) depending from the operational parameters

\begin{tabular}{ccccc}
\hline Run & $\begin{array}{c}\text { Organic loading rate (OLR) and } \\
\text { hydraulic retention time (HRT) }\end{array}$ & \multicolumn{2}{c}{ Obs./Theor., \% } & VSR, \\
& biogas & methane & $\%$ \\
\hline 1 & OLR 1.0 gVS/L-d; HRT 20 d & $48 \pm 5$ & $45 \pm 5$ & $64 \pm 5$ \\
2 & OLR 2.0 gVS/L-d; HRT 20 d & $43 \pm 4$ & $38 \pm 4$ & $59 \pm 4$ \\
3 & OLR 1.0 gVS/L-d; HRT 40 d & $55 \pm 5$ & $53 \pm 4$ & $73 \pm 6$ \\
4 & OLR 1.5 gVS/L-d; HRT 40 d & $34 \pm 3$ & $30 \pm 4$ & $55 \pm 6$ \\
\hline
\end{tabular}



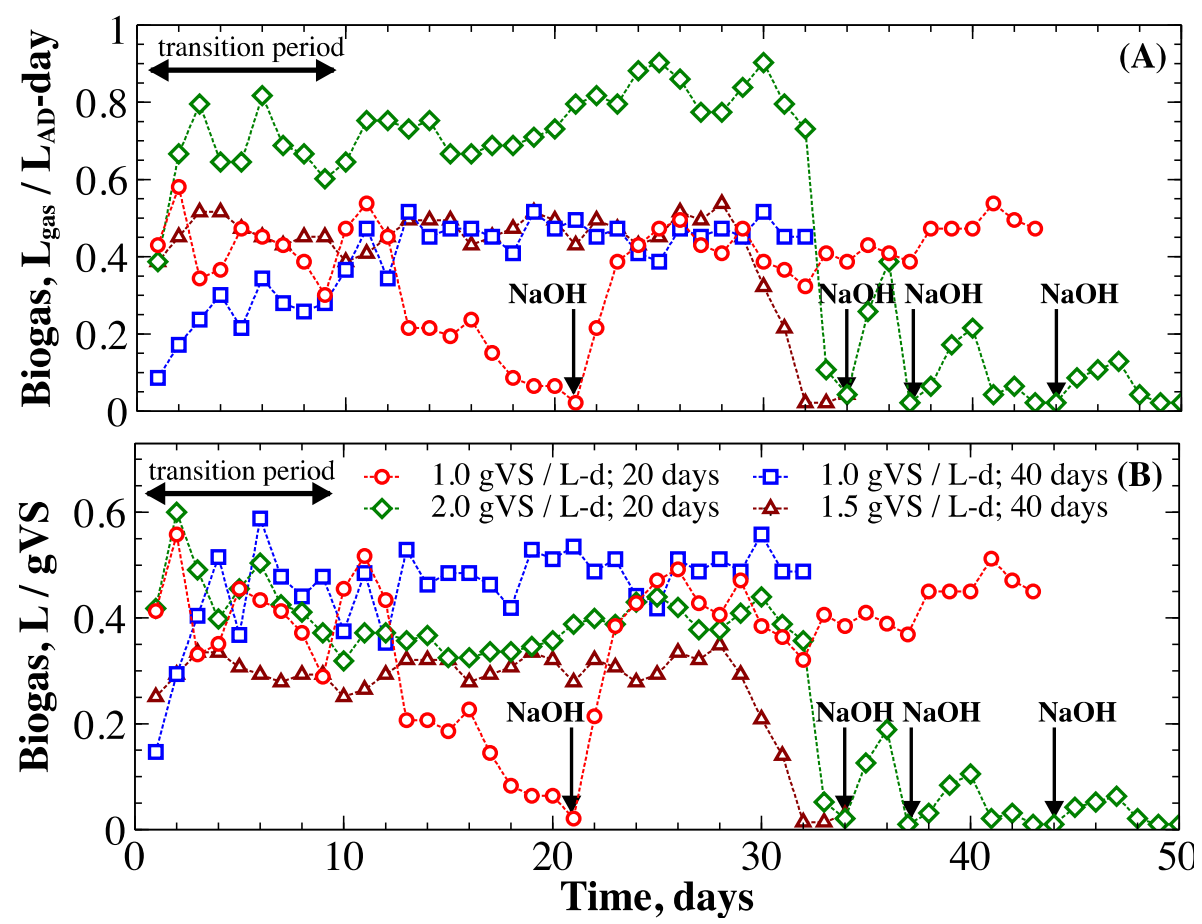

Figure 1. Average volumetric (A) and specific (B) biogas and methane production rates at four different operational regimes. 

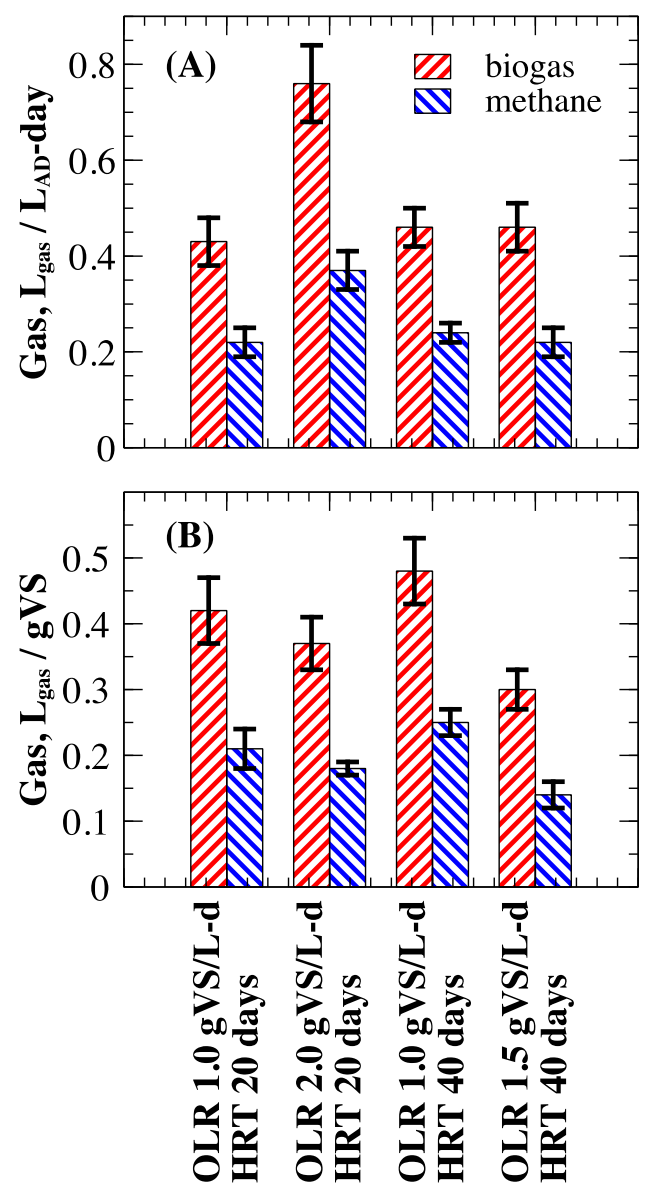

Figure 2. Average volumetric (A) and specific (B) biogas and methane production rates at different operational parameters. Error bars represent the standard deviation among daily gas productions during the stable period. 


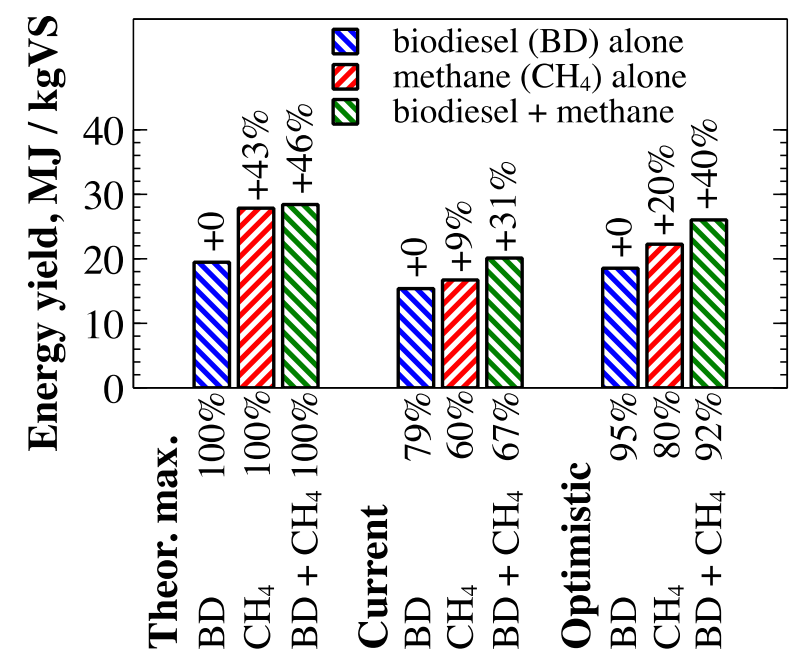

Figure 3. Theoretical maximum, current and projected optimistic scenarios of energy production per $1 \mathrm{kgVS}$ of algal biomass (total lipids $57 \%$, TAGs $45 \%$ of dry weight). 

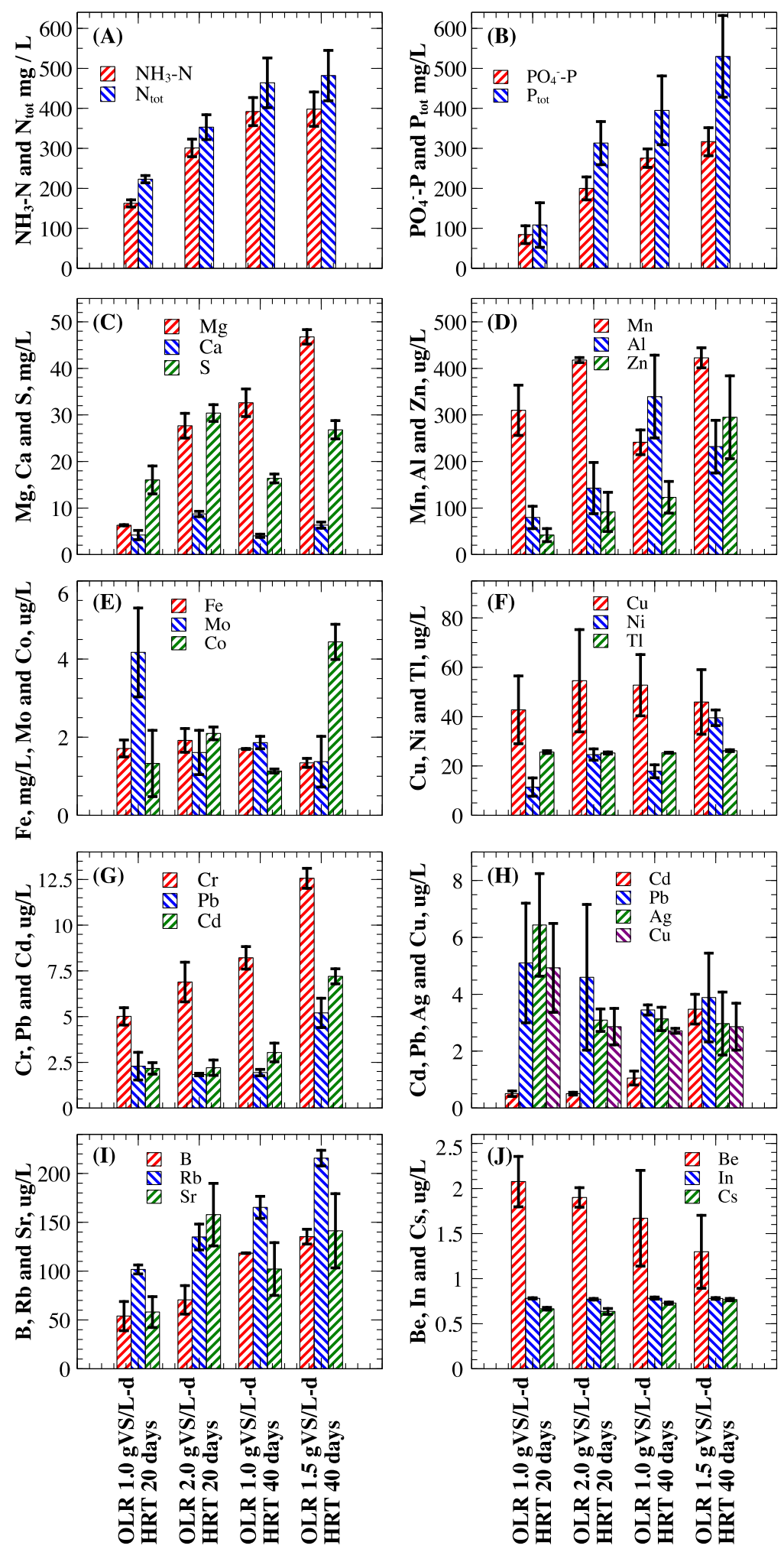

Figure 4. Concentration of elements in the soluble fraction of the digestate at different operational parameters. 

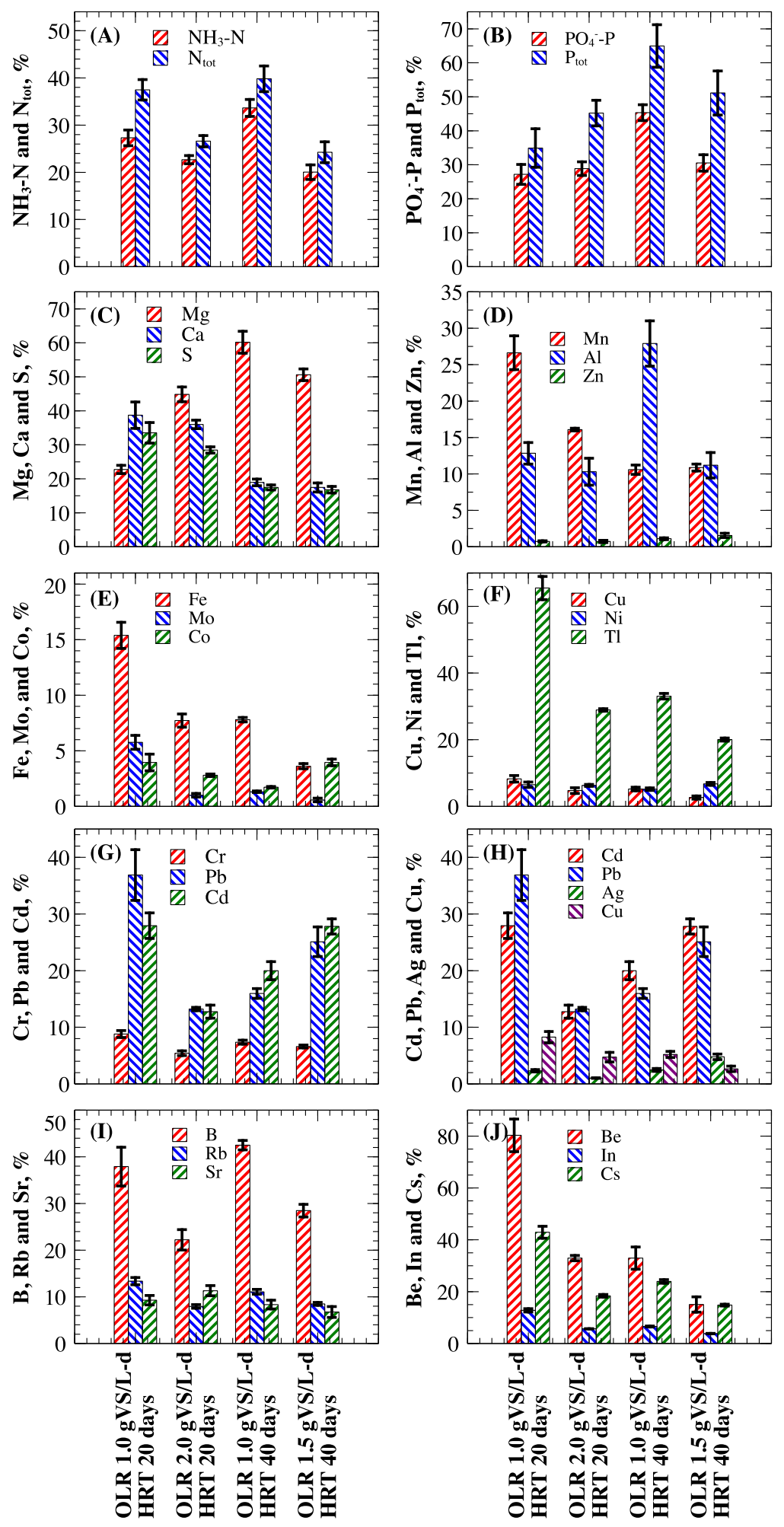

Figure 5. Fraction of elements concentrated in the soluble fraction of the digestate at different operational parameters. 

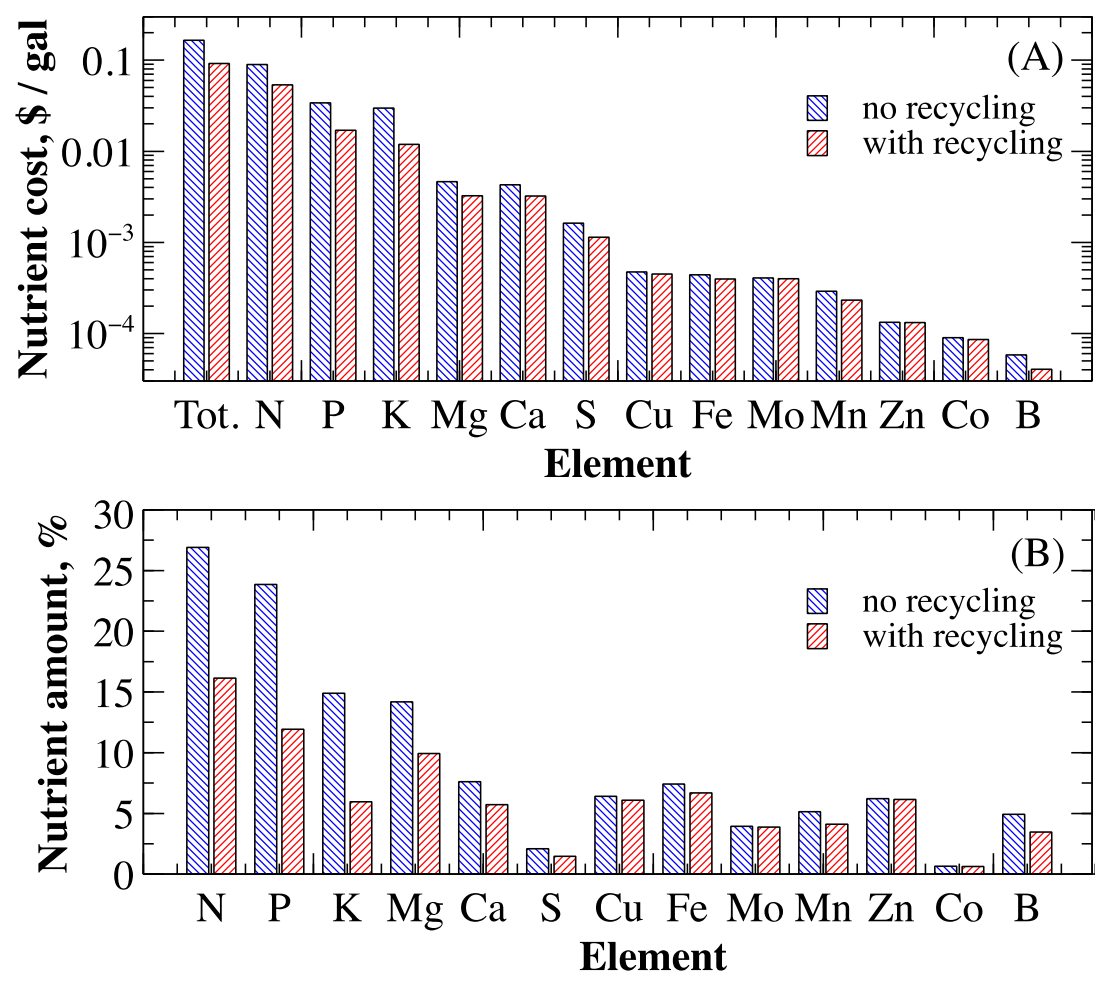

Figure 6. (A) Cost of nutrients required for production one gallon of algal biodiesel. (B) Nutrient amount required for generation of algal biodiesel equal to $10 \%$ of the current liquid fuel consumption in the U.S., as part of their current use in agriculture. 